\title{
HUAMACHUCO EN EL TIEMPO: ASIENTO URBANO Y ARQUITECTURA ${ }^{1}$
}

\author{
HUAMACHUCO ALONG TIME: URBAN SETTLEMENT \\ AND ARQUITECTURE ${ }^{1}$
}

Adriana Scaletti Cárdenas ${ }^{2}$

Lic. María Lucía Valle Vera ${ }^{3}$

\section{RESUMEN}

Huamachuco es una ciudad de la sierra del departamento de La Libertad (Perú) ubicada en un valle interandino a $3200 \mathrm{msnm}$; rodeado por zonas de gran importancia arqueológica -como Marcahuamachuco y Viracochapampa- y, más recientemente, por áreas de explotación minera. La ciudad, donde se libró la última batalla de la Guerra del Pacífico, se halla a 184 kilómetros de Trujillo, en la costa del país, pero en todo término excepto el espacial ha permanecido relativamente aislada de una serie de procesos nacionales. El objetivo de este artículo es entender el asentamiento desde las perspectivas histórica y arquitectónica, apuntando a revalorizar la cultura material que se conserva y a caracterizar la ciudad como poseedora de un interesante conjunto patrimonial.

\section{Palabras clave}

Historia regional, arquitectura tradicional, patrimonio cultural

\section{ABSTRACT}

Huamachuco is a city in the Highlands at the province of La Libertad (Peru), located in an interAndean valley at 3200 meters above sea level; it is surrounded by areas of great archaeological importance, such as Marcahuamachuco and Viracochapampa, and, quite recently, by mining activity areas. The city, where the last battle of the War of the Pacific occurred, is located 184 kilometers from Trujillo, on the northern coast of the country, but in every term, except the spatial one, it has remained relatively isolated from a number of national processes. The purpose of this article is to understand the settlement from the historical and architectural perspectives, aiming at the revalorization of the preserved material culture and at the characterization of the city as the holder of an interesting patrimonial collection.

\section{Keywords}

Regional history, traditional architecture, cultural heritage

1 Proyecto de Investigación acción "Transversal, acciones de integración en el territorio peruano" (2011-2016). Cofinanciado por la ARES, Comisión de la Cooperación para el Desarrollo del gobierno de Bélgica y la PUCP, Pontificia Universidad Católica del Perú. Participan las universidades, UCL, Universidad Católica de Lovaina, Facultad de Arquitectura, Ingeniería Urbanismo -Unidad de Arquitectura e Ingeniería-arquitectónica; ULg, Universidad de Lieja, Local Environment Management and Analysis, LEMA, y PUCP, Centro de Investigación de la Arquitectura y la Ciudad, CIAC, Departamento Académico de Arquitectura. Para Huamachuco, una de las cuatro localidades de estudio en el proyecto, participan además actores locales, Municipalidad Provincial de Sánchez Carrión, CEPPLAN, Centro Provincial de Planeamiento, Alcaldes vecinales, Instituto Superior Pedagógico José F. Sánchez Carrión, y líderes locales.

2 Arquitecta por la Universidad Ricardo Palma de Lima (Perú), Magister en Restauración de Monumentos por la Universidad La Sapienza de Roma (Italia), y Doctora en Gestión Cultural e Historia del Arte por la Universidad Pablo de Olavide de Sevilla (España).

3 Es bachiller y licenciada en Historia por la Pontificia Universidad Católica del Perú (PUCP). Actualmente, se desempeña como profesora del curso Orígenes del Cristianismo en la Facultad de Estudios Generales Letras de la PUCP y está realizando estudios de maestría en la misma institución. 


\section{INTRODUCCIÓN}

En el artículo elaboramos un perfil del desarrollo urbano y arquitectónico de la ciudad de Huamachuco en la historia, buscando presentarla en el contexto apropiado para su valoración patrimonial. Así, este se divide en cinco partes. En primer lugar, se presenta un recuento de la historia del pueblo de Huamachuco con el fin de poner en evidencia su relevancia histórica y cultural. En segundo lugar, iniciamos el estudio propiamente arquitectónico del complejo urbano de Huamachuco haciendo énfasis en los cambios realizados en la zona desde el asentamiento español y en la evidente influencia, términos matéricos, constructivos y estructurales, de la arquitectura cajamarquina. En tercer lugar, presentamos un análisis acerca de la arquitectura doméstica en Huamachuco, basada en el trabajo de campo que dio origen a esta investigación ${ }^{4}$. En cuarto lugar, comentamos dos casos representativos de arquitectura eclesial de Huamachuco: la capilla de San José y el campanario de la iglesia matriz, los edificios más notables del conjunto y de los más antiguos que se conservan. Finalmente, en quinto lugar, elaboramos una breve reflexión sobre el trabajo realizado, que muestra el valor patrimonial de los edificios del pueblo de Huamachuco y, con ello, la necesidad de políticas estatales de protección y conservación de patrimonio, y la participación activa de la población residente en el pueblo en aquella labor.

\section{PERFIL HISTÓRICO DE HUAMACHUCO}

La ciudad de Huamachuco, capital de la provincia de Sánchez Carrión, ha sido escenario de importantes acontecimientos de la historia peruana en sus distintos períodos: preinca, inca, virreinal y republicano. A continuación, presentamos un breve perfil del desarrollo político, económico, territorial, urbano y poblacional de Huamachuco teniendo en cuenta los diferentes contextos históricos mencionados. Conviene advertir que en la presente descripción haremos énfasis en los periodos virreinal y republicano, pues la mayor parte de muestras arquitectónicas halladas en la actual ciudad pertenecen a aquellos períodos.

En lo que respecta al período preinca, se tiene información de que después de la caída del imperio Tiahuanaco, "durante las behetrías ${ }^{5}$ serranas, pueblos yungas, probablemente mochicas, invadieron la región, diezmaron a la población residente y fundaron el Señorío de los Huamachucos" (Salcedo, 1954, p. 7). Este se configuró como un reino rico gobernado por un curaca principal (Lumbreras, 2013, p. 28 ), el cual contaba con un territorio extenso:

En su condición de reino o curacazgo comprendía los altos del río Chicama y la cuenca del Crisnejas (Pomarongón), por el norte; por el sur, las cuencas de los ríos Tablachaca, Chuquicara y Uchupampa, en el extremo septentorial del río Santa, en Áncash. Y llegaba desde el Marañón (Hatunmayo), por el este, hasta las nacientes de los ríos que están en la vertiente occidental del Pacífico. Limitaba con el reino de Chimor por el oeste, el Cuismanco o Gusmancu (Cajamarca) por el norte, el de los chachas por el este, y los de Conchucos y Huaylas por el sur. (Lumbreras, 2013, p. 28)

Entre los vestigios arqueológicos y arquitectónicos de la época, destacan las ruinas de Marca Huamachuco, las cuales se ubican a $10 \mathrm{~km}$ al norte de la actual ciudad y constituyen el "testimonio de la antigüedad y la densa población del lugar" (Tauro del Pino, 2001, VIII, p. 1195).

El reino de Huamachuco permaneció independiente hasta el siglo $\mathrm{XV}$, cuando fue

\footnotetext{
La investigación que se presenta nace en el marco del proyecto Transversal-Acciones de Integración en el Territorio Peruano, del CIAC y el Departamento de Arquitectura de la Pontificia Universidad Católica del Perú. El trabajo de campo involucró además el levantamiento arquitectónico y fotográfico de 15 edificios con presunción de valor patrimonial, realizado por los estudiantes de arquitectura PUCP Brayan C. Quenta, Olenka Palomino, Paul Ramírez y Carolina Zegarra en agosto 2014.

Antiguamente, población cuyos vecinos, como dueños absolutos de ella, podían recibir por señor a quien quisiesen (RAE)
} 
incorporado al dominio incaico bajo el reinado del inca Pachacútec (Minaya, 2012, p. 24; Lumbreras, 2013, p. 28; Tauro del Pino, 2001, t. VIII, p. 1195), iniciando así una segunda etapa de su historia. La presencia inca fue consolidada a través del posicionamiento del santuario, ciudadela y fortaleza de Marca Huamachuco y Wiracochapampa ${ }^{6}$, lugar de ceremonias cívico religiosas y, probablemente, militares (Minaya, 2012, p. 24).Después de ello, los incas dividieron el reino en seis waranqas, ${ }^{7}$ cuatro de ellas constituidas por mitayoqcuna (familias de origen étnico local) y dos por mitmaqcuna (mitimaes) o forasteros trasladados allí por el inca Huayna Cápac, según el expediente del cacique de Andamarca (Espinoza Soriano citado por Lumbreras, 2013, p. 28). De este modo, las comunidades de agricultores y pastores que poblaron el reino tributaban a los incas del Cusco (Lumbreras, 2013, p. 45).

En lo que respecta a su estatus urbano de Huamachuco en aquella época, Lumbreras señala que era el mismo que el de Cajamarca (en el reino de Cuismanco), Moyobamaba (en la tierra de los chachas orientales), Aypate (en la sierra de Piura) y también San Agustín del Callao (cerca de Quito):

Todos eran asentamientos incaicos de élite, y aunque carecían de la dimensión de ciudades como TomebambaIngapirca, Huanuco-pampa o Vilcashuamán- Punaqocha, que eran de primer orden, sí disponían de un trato especial, con ushnu, ${ }^{8}$ accllahuasi $^{9}$ y uno o dos recintos palaciegos, elegantes que estaban dentro de una cercado amurallado, en cuyo entorno estaban las viviendas construidas con material local y según los usos y costumbres de la zona (Lumbreras, 2013, p. 37)
Huamachuco también fue escenario de algunos de los eventos que marcaron dramáticamente el fin del incario y el inicio de la época virreinal. Durante la guerra por la sucesión inca emprendida por los hermanos Huáscar y Atahualpa (1530-1533), Huamachuco se convertiría en el lugar de la muerte de uno ellos. Mientras Atahualpa se encontraba en Cajamarca como rehén del conquistador Francisco Pizarro, le llegaron noticias de que Huáscar, mientras era trasladado como su prisionero a Cajamarca, se cruzó con los conquistadores Hernando de Soto y Pedro del Barco, quienes se dirigían a Cuzco, y les ofreció cuadriplicar el rescate de ofrecido por Atahualpa a cambio de su libertad. Así, temiendo que su hermano llegara a un acuerdo con los españoles, Atahualpa ordenó su ejecución (Tauro del Pino, 2001, VIII, p. 1231). Los capitanes de Atahualpa llevaron maniatado a Huáscar al río Antamarka ${ }^{10}$ (hoy río Tulpo) y lo ahogaron (Salcedo, 1954, p. 8). Una vez consolidada la dominación española con la ejecución de Atahualpa (el 26 de julio de 1533) y el sometimiento de la población indígena, Huamachuco pasó a formar parte del Corregimiento de Cajamarca junto con las provincias de Cajamarca y Los Huambos.

En 1551 los padres agustinos llegaron a la región y fundaron una casa de religiosos donde se ubicaba el tambo real de los Incas, casa que fue elevada al rango de convento en 1554 . Y en 1553, fundaron el pueblo de San Agustín de Huamachuco bajo la advocación de la Virgen de Alta Gracia, patrona de la orden (Minaya, 2012, p. 24; Salcedo, 1954, p. 8). Asimismo, construyeron la Iglesia Matriz cuyo anexo fue la casa de ejercicios y cristianización que en la actualidad es el local del Colegio Nacional "San Nicolás".

En su etapa como provincia del Corregimiento de Cajamarca, en el período de 1565-1759,

Ubicada cerca de la ciudad de Huamachuco, en el cerro Sansón (Middendorf, 1975, p. 224).

O unidades de mil tributarios (Lumbreras, 2013, p. :28)

8 Construcción en forma de pirámide trunca usada para presidir las ceremonias imperiales más importantes del asentamiento, generalmente ubicado al interior del espacio de una gran plaza. Véase al respecto Canziani, José. Ciudad y Territorio en los Andes: Contribuciones a la historia del urbanismo prehispánico. Lima: Fondo Editorial de la Pontificia Universidad Católica del Perú, 2009, p. 469.

9 "Casa de aqllas" (Pease, 2007, pp. 144-1445). Véase el ejemplo del Cusco en Canziani, J. Ciudad y Territorio..., p. 444.

10 Muchos historiadores - entre ellos el propio Espinoza Soriano- sostienen que, efectivamente, Huáscar fue capturado en el norte del Perú. 
el descontento social del campesinado ante la gestión de la Real Hacienda fue constante, lo que desencadenó en la sublevación de los huamachuquinos en 1758, siendo esta la principal motivación para que el virrey Manso de Velazco se decidiera reorganizar la provincia (Espinoza Soriano, 1992, p. 24). Para ello, propuso segregar la provincia de Huamachuco del Corregimiento de Cajamarca para convertirla en un Corregimiento autónomo, gobernado por su propio corregidor (Espinoza Soriano, 1992, p. 24). Fue así como el 11 de enero de 1759 se expidió el Auto en el que se dispuso la segregación y el 15 de febrero se despachó un Decreto Superior que apoyó lo ordenado en el Auto (Espinoza Soriano, 1992, p. 25). Siguiendo el proceso, el 8 de mayo de 1760, el fiscal de las Indias consideró válidas las razones presentadas por el virrey para realizar la separación de la provincia de Huamachuco y derivó el caso al rey para que lo aprobara. Después, el Consejo de Indias emitió en dos pareceres el 16 y 20 de mayo su conformidad con la decisión del virrey del Perú. De ese modo, el 16 de junio de 1760 el rey expidió la resolución por la que ordenaba cumplir con lo dictaminado por el Consejo, y determinó que la Cámara de Indias designara a las personas que debían ocupar el cargo de corregidor en Huamachuco y Cajamarca, respectivamente (Espinoza Soriano, 1992, p. 28-29). Luego, el 14 de julio de 1760 en el Buen Retiro, fue despachada la real cédula que aprobó el Decreto del 15 de febrero de 1759, confirmando así la creación del Corregimiento de Huamachuco. Dicha cédula, cuando llegó a Lima, fue recibida por el virrey Manuel de Amat y Juniet, quien hizo elaborar una copia para difundir la noticia. Envió la cédula original a Huamachuco y otra copia a Cajamarca para que se cumpliera la disposición real (Espinoza Soriano, 1992, p. 29). El nombre del Corregimiento se debió a que, territorialmente, solo comprendió la provincia de Huamachuco y sus principales autoridades, el curaca principal y gobernador, pasaron a llamarse "cacique y gobernador de los siete pueblos del Corregimiento de Huamachuco" y "corregidor de la provincia de Huamachuco y el Valle de Condebamba" respectivamente (Espinoza Soriano, 1992, p. 30). El primer corregidor fue nombrado por el virrey en 1759 , mientras que otros funcionarios tardaron en ser nombrados; por ejemplo, el escribano público fue nombrado recién en 1765 (Espinoza Soriano, 1992, p. 30).

La extensión territorial del Corregimiento fue de 11,326.44 kilómetros cuadrados (Espinoza Soriano, 1992, p. 32). Por el oeste, sus límites han permanecido iguales desde 1759 hasta la actualidad. Por el norte, son los mismos que hoy separan las provincias de Otuzco y de Cajabamba de las de Contumazá y Cajamarca. Por el sur, el límite fue el mismo lindero que actualmente divide la provincia de Santiago de Chuco de las de Corongo, Pallasca y Santa (Espinoza Soriano, 1992, p. 32). Por el este, se mantiene igual que en el virreinato. A lo dicho, se puede agregar que el Corregimiento, en el siglo XVIII, comprendió seis términos ${ }^{11}$ : San Nicolás de Cajabamba, Santiago de la Lucma, San Pedro y San Pablo de Usquil, La Pura y Limpia Concepción de Otuzco, Santiago de Chuco y San Agustín de Huamachuco, que fue la cabecera ${ }^{12}$ de la provincia (Espinoza Soriano, 1992, p. 34).

El término de San Agustín de Huamachuco se encuentra ubicado en la parte central y sudoeste del corregimiento. "Sus límites fueron: por el norte, el término de Cajabamba; por el este, el río Marañón; por el sur, el corregimiento de Conchucos y el término de Santiago de Chuco; por el oeste, con los de Usquil y Santiago de Chuco nuevamente. Asimismo, comprendió un pueblo, San Agustín de Huamachuco (capital del corregimiento) y veintiséis haciendas y estancias, las cuales son las siguientes: Chuyugual, San Felipe de Chuzgón, Pampatac, La Succha, Moyán, Candoval, Yamán, Marcabal Grande, Santa Rosa de Iracapampa, Chichir, Caracmaca, Algamarca, Sanagorán, Soquián, San Nicolás

\footnotetext{
11 Este término colonial es sinónimo de distrito republicano (Espinoza Soriano: 1992, p. 34).

12 Nombre con el que se designaba la capital de un término. La cabecera de Huamachuco, a diferencia de otras que eran villas y ciudades, tuvo la categoría de pueblo que era lo más común en la región (Espinoza Soriano, 1992: 34).
} 
de Jucusbamba, Higospata, Pomabamba, Quilcaymachay, Sartimbamba del Marañón, Marcabal Chico, Sancobamba, Serpaquino, Sarín, Los Chunchos, Llaupuy" (Espinoza Soriano, 1992, p. 36)

Además, el término contaba con lugares muy importantes y los que es necesario describir para comprender el desarrollo urbano del distrito principal del corregimiento y la vida cotidiana de los pobladores. El primer lugar en mencionar es el pueblo de San Agustín de Huamachuco, capital del corregimiento. Fue fundado en 1565 como reducción indígena por el teniente Marcos Pérez Gutiérrez y el padre fray Juan de San Pedro (Espinoza Soriano, 1992, p. 36). Desde 1565, el pueblo fue la cabecera de la provincia de Huamachuco, y cuando la provincia fue convertida en un corregimiento independiente siguió conservando su categoría, ya que el corregidor vivió allí. Aunque no ofrecía un ambiente agradable para el viajero, debido a su ubicación en un paraje frío, fue el pueblo más concurrido por su importancia (3 Espinoza Soriano, 1992 , p. 6). Su plano fue muy irregular, sus calles eran estrechas y muy poco rectas y las casas carecían de estética (Espinoza Soriano, 1992, p. 36). A pesar de ello, tuvo la Plaza Mayor más grande de la provincia, la cual no contaba con mayor atractivo que la vegetación que brotaba en los días de invierno (Espinoza Soriano, 1992, p.36). Tuvo varias iglesias, siendo la más importante la iglesia Matriz (Espinoza Soriano, 1992, p. 36). En lo que respecta a la producción del pueblo, Espinoza Soriano comenta lo siguiente:

En sus términos distritales la agricultura no floreció como en Cajabamba, de manera que sus cosechas de trigo, ocas, papas, cebada, habas, etc. fueron pobres, aunque la alfalfa sí se dio muy bien. Asimismo, careció de buenas minas (...) Dos de las minas que existieron en sus términos, muy paupérrimos desde luego, fueron las de Huangacocha, a $20 \mathrm{kms}$ de
Huamachuco, y la Aupillan, la misma que también fue conocida después con los nombres de Mina Hedionda y de La Trinidad. Fue de hierro. (1992: 37)

Como se puede apreciar por la cita, se tiene que la capital del término de San Agustín de Huamachuco no contaba con suficientes recursos minerales ni agrarios de calidad para poder destacar, por lo que su importancia se ve sustentada en la tradición y en la presencia de la principal autoridad de Corregimiento.

Un segundo lugar del término de que debe ser mencionado es la estancia de Chusgónhacienda que perteneció a los agustinos de Lima- la cual fue una de las más importantes del término. Su extensión fue amplia, pues "sus linderos comenzaron en la capital del Corregimiento y se dilataban los límites con los límites de Cajabamba y de Santiago de Chuco" (Espinoza Soriano, 1992, p. 37). Al estar muy poblada, recibió el nombre de asiento ${ }^{13}$ de la estancia de Chusgón. Su producción fue rica, se cosechaba gran cantidad de maíz y los pastos alimentaron diversos ganados como el vacuno, equino, y especialmente, ovino. La lana fue invertida en la elaboración de pañetes. Además, su clima cálido propició el cultivo de frutas como naranjas, limones y pacaes (Espinoza Soriano, 1992, p. 37).

El tercer lugar a mencionar es la hacienda Llautobamba, la cual se ubicaba a diecisiete leguas de Huamachuco. No fue una hacienda grande, pero su ubicación entre la puna y las orillas del río Marañón hizo que gozara de variedad de climas. (Espinoza Soriano, 1992, p. 37). El cuarto lugar es la hacienda Sancobamba, ubicada entre la estancia del Chusgón y la hacienda Llautobamba. Esta produjo trigo, maíz, alverjas, quinua, habas y papas (Espinoza Soriano, 1992, p. 37-38). El quinto lugar es la hacienda Sartimbamba, que se ubicaba a once leguas de Huamachuco. "En 1821 adquirió la categoría de pueblo. Desde entonces fue la cabecera de la doctrina del

13 Fue la categoría en con la que se identificaron distintas estancias, haciendas y obrajes que albergaban a una gran cantidad de población compuesta principalmente por indígenas yanaconas y mitayos que trabajaban sobre todo en el pastoreo, en los trapiches, en la agricultura y en los obrajes. (Espinoza Soriano, 1992, p. 35). 
mismo nombre. Fue considerada como doctrina $\mathrm{N}^{\circ} 2$, seguidamente de la de Huamachuco, en cuanto a proventos se refiere" (Calderón Rebaza citado por Espinoza Soriano, 1992, p.38). El sexto lugar es la mina Sanagorán, la cual produjo plata de excelente calidad y fue un asiento (Espinoza Soriano, 1992, p. 38)

Otros lugares son los cerros Shocop y Cushil que estuvieron próximos al asiento Sanagorán, que también produjeron plata de buena calidad. Dejaron de ser trabajadas cuando iniciaron las guerras de Independencia. Debido al abandono y las constantes lluvias aquellas casi desaparecieron (Espinoza Soriano, 1992, p. 38). También se pueden mencionar al Cerro Negro y el cerro El Toro. Del cerro El Negro se extrajo plata y fue abandonado cuando su dueño huyó durante las guerras de Independencia. Por su parte, el cerro El Toro, ubicado al sureste de Huamachuco produjo oro, plata y cobre. Sin embargo, en 1789 hubo una inundación de agua y los dueños, a pesar de sus esfuerzos, no pudieron repararla (Espinoza Soriano, 1992, p. 38). Finalmente, se tiene la hacienda Serpaquino, la cual era extensa y poseía algunas vetas de plata. Perteneció a ella el ingenio de Chichir, y uno de sus grandes atractivos fue un puquio de agua termal y ferrugimosa ubicado a 7 kilómetros de la Casa-Hacienda (Espinoza Soriano, 1992, p. 38)

Para entender aún más la distribución y organización del Corregimiento de Huamachuco durante la época virreinal resulta necesario comentar acerca de las demarcaciones eclesiástica y económica de la región. Por un lado, la demarcación eclesiástica del corregimiento de Huamachuco no coincidió con la política ni económica del mismo (Espinoza Soriano, 1992, p. 50). Además de las seis doctrinas o curatos que pertenecieron a cada una de las cabeceras de los seis términos políticos del corregimiento, hubo dos más integrados por estancias y haciendas, debido a la gran cantidad de población que residía en ellas. Además, otro grupo de haciendas ubicadas al oeste del término de Cajabamba conformaron, desde 1592, una sola demarcación eclesiástica con el término distrital de El Real de San Jerónimo de Ichocán, el cual perteneció políticamente a la provincia de Cajamarca (Espinoza Soriano, 1992, p. 50). Estas demarcaciones eclesiásticas recibieron el nombre doctrinas y durante la segunda mitad del siglo XVIII se les conoció como curatos ${ }^{14}$ los cuales fueron: San Agustín de Huamachuco, San Nicolás de Cajabamba, Santiago de La Lucma, San Pedro y San Pablo de Usquil, La Pura y Limpia Concepción de Otuzco, Santiago de Chuco, Sinsicap, Las Estancias (subdividido en cuatro partidos: Jucusbamba, Marcabal, San Pedro de Chuquisongo y Mollepata) y el anexo de Amarcucho. Y las demacraciones eclesiásticas conformadas por latifundios, se les denominó Curatos de las Estancias (Espinoza Soriano, 1992, p. 50-51)

Por otro lado, la demarcación económica comprendió la misma área jurisdiccional de su demacración política, incluyendo el término de San Juan de Simbal, el cual políticamente pasó a formar parte de la provincia de Trujillo desde los primeros años del siglo XVIII. Por ello, el corregidor y el curaca principal tuvieron jurisdicción sobre los habitantes de Simbal en lo que respecta a cuestiones tributarias y a la prestación de servicios personales por parte de los indígenas (Espinoza Soriano, 1992, p. 55)

En lo que respecta a la población, Tauro del Pino comenta que cuando el arzobispo Toribio Alfonso de Mogrovejo visitó Huamachuco en 1593, este albergaba 3,987 indios; y dos siglos más tarde, la población se redujo a 2,157 , en un total de 5,125, que además incluía a 2,624 mestizos, 265 españoles y criollos, 21 esclavos negros y 44 individuos de otras razas (2001 VIII: 1195). Para la primera mitad del siglo XVIII, Espinoza Soriano señala que no hay documentos que den a conocer el número de habitantes de Huamachuco, solo se puede calcular el número de tributarios que habitaron en el Corregimiento de la provincia

\footnotetext{
14 A partir de 1821 a los curatos se les pasó a denominar parroquias, terminología que dura hasta la actualidad (Espinoza Soriano, 1992, p. 50).
} 
de Huamachuco (Espinoza Soriano, 1992, p. 64). En 1778, el Corregimiento tenía siete pueblos dentro de su demarcación económica. "En ellos, vivieron 485 habitantes, los cuales recibieron el nombre de "indios poblanos" o sea residentes en un pueblo" (Espinoza Soriano, 1992, p. 69). Fuera de los centros urbanos vivieron 1311 indígenas tributarios. Asimismo, hubo 2132 hubo forasteros quinteros tributarios y 223 tributarios forasteros procedentes de Cajamarca. Posteriormente, el censo de 1797 registró 38,978 habitantes y once años más tarde, en mayo de 1808 el censo registró 55, 978. Pero el aumento de la población se debió a las alianzas matrimoniales dadas entre las poblaciones mestiza y criolla. Por su parte, la población indígena disminuyó (Espinoza Soriano, 1992, p. 69)

En general, en lo que respecta a la economía se puede decir que, durante el siglo XVIII, el corregimiento de Huamachuco fue muy parecido al de Cajamarca. Sin embargo, la principal diferencia entre ambos fue que Huamachuco tuvo minas de plata más ricas, pues Hualgayoc no se descubrió sino hasta 1772, (Espinoza Soriano, 1992, p. 5) y tuvo algunas de oro. De las pocas que se trabajaron se pueden mencionar las siguientes: El Cerro Algamarca, El Cerro San José, El Cerro Achocamas y El Cerro Rico de Carangas, el Cerro Aupillán (donde hubo vetas de hierro). También existieron minas de azufre y canteras con piedra imán (Espinoza Soriano, 1992, p. 6)

Los pobladores, además de la minería, se dedicaron a la alfarería y la textilería de lana y algodón. Esta última actividad fue la más destacada en la región, pues las frazadas, ponchos, pañolones, alfombras y caronas que produjeron los pobladores en los obrajes gozaron de especial aprecio en el mercado local e interprovincial (Espinoza Soriano, 1992, p. 6)

A diferencia de las actividades antes mencionadas, la industria en la provincia y Corregimiento de Huamachuco fue subdesarrollada, lo mismo que la agricultura. La tierra de las haciendas fue trabajada de manera rudimentaria y se producía solo lo necesario para el consumo. Aquellos productos fueron los siguientes: maíz, trigo, cebada y papas. En cuanto a las frutas, se cosechaban tanto aquellas propias de climas fríos como calientes (Espinoza Soriano, 1992, p. 6)

A diferencia de la industria y la agricultura, la industria ganadera y textil sí prosperaron, lo que se refleja en los numerosos obrajes y las modernas fábricas que existieron en Huamachuco. Estas producían productos para satisfacer la demanda de vestido a nivel regional de las provincias vecinas, excepto Cajamarca y Chachapoyas que eran sus competidoras. En el siglo XVIII existieron en Huamachuco veintiséis fábricas de textiles $\mathrm{u}$ obrajes y tres chorrillos o pequeños obrajes. Entre los obrajes estaban los siguientes: Carabamba (de los agustinos), Sinsicap (de la Comunidad), Chusgón (de los agustinos), San Juan Bautista de Marabamba, Santa Cruz de la Caracmaca, Jancos, Yamobamba, San Cayetano de Ramobamba, Chonta, Yagén, Chuquisongo, Capachic, Yanahuanca, Porcón, Angasmarca, Llaray, Llauqueda (actualmente Llaqueda), San Ignacio, Chota, Moncachap, Cajabamba, Sangual, Uningambal, Motil, Capachique y El Tulpo (Espinoza Soriano, 1992, p. 7). Y los tres chorrillos fueron: Oyón, La Colpa y Cachicadán (Espinoza Soriano, 1992, p. 7)

Avanzando en la historia, se tiene que la población de Huamachuco no fue indiferente ante los acontecimientos que llevaron a la independencia del Perú, sino todo lo contrario. Aquella participó activamente financiando al ejército libertador con diversos recursos tales como: dinero, hombres, víveres, armamento, entre otros. Sus acciones le valieron el título de "muy ilustre y fiel ciudad" otorgado el 12 de junio de 1821 (Tauro del Pino: 2001, VIII, p. 1195). Luego de proclamada la independencia del Perú por el general don José de San Martín, este estableció el Protectorado y fundó la Sociedad Patriótica a fin de debatir el sistema político que debía regir en el Perú. Una vez más, el prestigio de Huamachuco se hizo sentir en la figura de don José Faustino Sánchez Carrión, pensador político de tendencia liberal quien, contrariando al deseo de San Martín y su ministro Bernardo de Monteagudo de 
establecer una monarquía en el Perú, defendió la instauración de un gobierno republicano, y esto lo hizo a través de la redacción de tres cartas firmadas con el seudónimo de "El solitario de Sayán". Su sólida argumentación tuvo como resultado la adopción del régimen republicano (Tauro del Pino: $2001 \mathrm{XV}$ : 2363) Además, destacó por su colaboración en periódicos como Correo Mercantil, La Abeja Republicana y El Tribuno de la República Peruana (Tauro del Pino: 2001, XV, p. 2363-2364)

Asimismo, Sánchez Carrión fue elegido diputado por Trujillo, se incorporó al primer Congreso Constituyente, en el cual organizó la secretaría (del 20 de setiembre a 20 de noviembre de 1822), integró la comisión encargada de la redacción de la primera Constitución, se opuso a la designación de una junta gubernativa y abogó para que se convocara a Simón Bolívar a continuar la guerra de independencia (Tauro del Pino: 2001, XV, p. 2364). El Congreso acogió esta última proposición en junio de 1823, por lo que se les designó a él y al poeta José Joaquín de Olmedo que viajaran a Guayaquil a efectuar dicha invitación, la cual fue aceptada con agrado por parte de Bolívar (Tauro del Pino, 2001 XV, p. 2364)

Bolívar tuvo una estancia prolongada en Huamachuco, entre el 21 de abrily el 10 de mayo de $1824 .{ }^{15}$ Bolívar se hospedó en la casona de Sánchez Carrión, quien se convirtió en uno de sus principales colaboradores, y estableció allí su cuartel general, pues consideraba a la ciudad un punto estratégico importante para abastecer sus tropas y posibilitaba un acceso rápido a la sierra central para combatir a las tropas realistas (Alva Castro, 2003, p. 44). Con la independencia realizada, Huamachuco geográficamente conservó el territorio que tuvo durante el virreinato; sin embargo, por diversos motivos políticos y administrativos, se fueron segregando otras provincias Otuzco, Cajabamba y Santiago de Chuco (Salcedo, 1954, p. 9)
A finales del siglo XIX, Huamachuco destacaría nuevamente en la historia peruana al ser el escenario del enfrentamiento final entre los ejércitos de Perú y Chile en la Guerra del Pacífico (1879-1883). El 10 de julio de 1883, a las 10 de la mañana, las tropas de Andrés A. Cáceres conformadas por 1,600 soldados se enfrentaron a 2,000 soldados chilenos dirigidos por el coronel Eustaquio Gorostiaga (Tauro del Pino, 2001, VIII, p. 1195). La batalla se intensificó en la llanura de Purubamba y todo parecía indicar que terminaría a favor del ejército peruano, pero la falta de municiones determinó irremediablemente la victoria del ejército chileno. Las tropas peruanas sufrieron 700 bajas; quedaron heridos Cáceres y otros dirigentes, y el coronel Leoncio Prado, quien también se encontraba herido, fue capturado y ejecutado por el ejército chileno dos días después (Tauro del Pino, 2001, VIII, p. 1195). Esta derrota de la resistencia peruana llevó al final de la Guerra del Pacífico teniendo como resultado la victoria del país del sur.

A lo expuesto habría que agregar que en estas últimas décadas del siglo XIX contamos con información sobre la vida cotidiana y el estado de la ciudad de Huamachuco a través de los testimonios de viajeros que realizaron expediciones científicas al Perú y otras partes de Sudamérica. Uno de aquellos testimonios es el de Charles Weiner, explorador y diplomático francés, quien viajó a Huamachuco en 1880. Weiner destaca fascinado las ruinas de Marca Huamachuco (compuesta por cuatro barrios llamados: el Castillo, los Corrales, la Falda con la Monja, y el Cerro Viejo) y Wiracochapampa (cuyas mejores piedras eran extraídas por los pobladores para construir las paredes de sus casas), así como la capilla de San José. Sobre las calles, advierte que las están orientadas según los cuatro puntos cardinales, lo cual se debe a las creencias y legado arquitectónico de los antiguos residentes. En lo que respecta a la población, la información que proporciona por el explorador y diplomático es limitada. Comenta que los indios no tenían un oficio y cómo a las rabonas, mujeres de los soldados, se

15 El 10 de mayo de 1824, último día de la estancia de Bolívar, se decretó la creación de la Universidad de Trujillo (Alva Castro, 2003, p. 44). 
les considera sufridas, valientes y contentas de su miseria (Weiner, 1993, p. 156). Asimismo, describe las condiciones precarias del trabajo de los oficiales y los conflictos con los indios.

Otro viajero con cuyo testimonio contamos es Ernst Middendorf, médico y antropólogo alemán. En su obra Observaciones y estudios del país y sus habitantes durante una permanencia de 25 años (1895), describe la ciudad de Huamachuco como similar a otras poblaciones serranas "tiene las mismas casas opacas a lo largo de las calles estrechas y mal pavimentadas, una gran plaza rectangular, en uno de cuyos lados está la iglesia, cuya pila, toscamente labrada, carente de agua, que se encuentra en el centro de la plaza, no contribuye precisamente a embellecerla" (Middendorf, 1973, III, p. 222)

En lo que respecta a la población, el viajero alemán informa que Huamachuco contaba con tres mil habitantes, conformada en su mayoría por indios puros que hablaban español, pues el idioma quechua habría sido casi completamente desplazado (Middendorf, 1973, III, p. 222). Los humachuquinos, como en la época virreinal, se dedicaban a la agricultura, la ganadería y muchos también eran arrieros. Además, señala que debido a las zonas pantanosas del valle y a las laderas empinadas y pedregosas de los cerros, las chacras de los pobladores se encontraban en los valles vecinos. Las mujeres se especializan en la confección de tejidos finos, siendo los chales los más solicitados (Middendorf, 1973, III, p. 222). El clima era fresco y la vegetación escasa. Por un lado, se apreciaban en el paisaje muchos saúcos arbóreos y quisuares. Por otro lado, el maíz ya no crecía, por lo que se cultivaba un poco de trigo y abundante cebada (Middendorf, 1973, III, p. 222)

En lo que respecta a las ruinas, al igual que Weiner, Middendorf mostró mucho interés en Marca Humachuco y Wiracochabamba, cuya construcción y asentamiento estuvieron condicionados por las particularidades de los cerros en los que se construyeron. Esta adaptación al medio, característica de las culturas andinas prehispánicas, resalta de modo particularmente elegante en el caso de Marca Huamachuco, y nos habla de la importancia y cuidado con que el urbanismo y la arquitectura en general eran trabajados en esta región incluso antes de la llegada de los incas, y muchos siglos antes del asentamiento virreinal que es cuanto hoy conocemos.

En lo que respecta al siglo XX, como comenta el antropólogo Elías Minaya, Huamachuco ha cumplido de forma mínima su rol político administrativo debido a la débil presencia estatal y al predominio del sistema latifundista. En lo que respecta a la economía local, esta se caracteriza por la configuración de mercados tradicionales y ferias semanales (Elías Minaya, 2012, p. 25)

Sobre la población se tiene que, con la aplicación de la reforma agraria de 1969, esta se ha conformado de campesinos emprendedores con deseos de renovar la fisonomía de sus pueblos, modernizar sus mercados y las relaciones de intercambio en sus propias comunidades y su entorno (Elías Minaya, 2012, p. 25). A este contexto habría que agregar la influencia de la empresa canadiense Barrign que, desde la década de 2000, encarga de la explotación de las minas de Misquichilca. Con ello, "se están ampliando la dinámica de interrelación demanda oferta de bienes y servicios diversos haciendo de la ciudad de Huamachuco la sede del surgimiento de nuevos negocios y su irradiación correspondiente a su hinterland" (Elías Minaya, 2012, p. 25). Finalmente, se debe reconocer el rol que ha asumido el gobierno municipal con el propósito de liderar el proceso de descentralización a niveles subregional y regional (Elías Minaya 2012, p. 25)

\section{HUAMACHUCO: ASIENTO URBANO, MATERIALIDAD, ARQUITECTURA}

Como se ha mencionado, no existen vestigios que nos indiquen con precisión la configuración urbana prehispánica de Huamachuco, aunque remanentes en la forma de hitos tales como los basamentos de la capilla San José y la Catedral nos presenten algunos indicios. Sabemos que en los tiempos en que funcionó como tambo, la traza probablemente incluyó 
los componentes incaicos de ortogonalidad, aunque sus dimensiones y extensión no son claras.

La ocupación del territorio por parte de los españoles significó, como vimos, el establecimiento de una reducción de indios, que luego fue creciendo hacia pueblo $y$ villa. Presumiblemente en este momento fue cuando se superpusieron construcciones para el servicio de la iglesia católica sobre hitos indígenas - las mencionadas capilla y catedral- y se establecieron, por lo menos esquemáticamente, las líneas del asentamiento virreinal. Estas líneas, continuando con ese supuesto, serían prácticamente las mismas que hoy determinan el centro histórico de la ciudad de Huamachuco sobretodo en el área de la plaza principal, y en sus alrededores inmediatos. Alejándonos más de esta zona, puede leerse claramente que hay sectores urbanizados que han sido diseñados $\mathrm{O}$ modificados para la expansión en tiempos muy recientes: agréguese a esto las dimensiones de calles y avenidas planeadas para el transporte vehicular, la permisividad de autoridades pasadas en cuanto a construcciones de toda dimensión y altura, y el degrado y el abandono de los edificios históricos; baste ello para entender que Huamachuco no es hoy por hoy la ciudad homogénea que fue hasta el siglo XIX.

A pesar de pertenecer - como se ha vistodurante muchos años al Obispado de Trujillo, en Huamachuco resulta inmediatamente evidente que la principal influencia en términos arquitectónicos, matéricos, constructivos $y$ estructurales de la ciudad histórica que hoy resta -fundamentalmente virreinal y republicana temporalmente - es sin duda cajamarquina. ${ }^{16}$ A partir de ese centro urbano, principal de los Andes del norte peruano, conceptos constructivos y espaciales comunes a toda la sierra virreinal adquieren una personalidad característica cuyas raíces pueden leerse en la particular variedad que de la misma se expresa en Huamachuco. Así, nos concentraremos un momento en las diferencias antes que en las similitudes, teniendo a Cajamarca como línea base.

Un tema particularmente relevante es el del método y material constructivo: mientras que en Cajamarca y otros pueblos y ciudades andinos lo preponderante es la presencia del adobe en los conjuntos urbanos y el tapial más bien en zonas de las afueras, en el Huamachuco tradicional la mayoría de los muros están conformados en base a gruesos muros de tapial - con un promedio de 65 $\mathrm{cm}$ de ancho- con apenas resanes y rellenos cuando resulta necesario con unidades de adobe sobre cimientos y sobrecimientos de piedra.

Vanos de todo tipo siguen la tendencia general dependiente del clima serrano $y$ de las características del material, siendo relativamente limitados $\mathrm{y}$ de dimensiones contenidas. En muchísimas ocasiones, las jambas y dinteles se muestran derramados, es decir, cortando el muro en que se encuentran de tal manera que el vano es ligeramente más estrecho y bajo hacia el exterior que hacia el interior. ${ }^{17}$ Algunas diferencias aparecen claramente en este punto respecto al referente cajamarquino: por ejemplo, no se observan portadas de piedra marcando el ingreso principal y representativo de residencias y edificios públicos. En cambio, encontramos un sutil uso de la escala y la proporción para dar esta indicación; y en lugar de piedra, delgadas jambas de madera tallada que enmarcan puertas y ventanas principales, frecuentemente con un zócalo bajo decorativo.

Los arcos en los vanos de edificios civiles son extraordinariamente infrecuentes, y ni siquiera se encuentran en los zaguanes o los corredores hacia segundos patios (aunque hay unos pocos casos), como en cambio sí sucede en

\footnotetext{
${ }_{16}$ Hoy, por otra parte, la relación comercial y cultural pasa fundamentalmente por Trujillo, impulsado por conexiones carreteras y de relación con la capital.

17 Esta estrategia para aprovechar la luz y ventilación frecuentemente se encuentra en combinación con las jambas derramadas pintadas de blanco, buscando disminuir el contraste lumínico interior-exterior. Véase al respecto los trabajos del arquitecto Martín Wiesser (PUCP).
} 
prácticamente todas las ciudades peruanas de configuración arquitectónica virreinal. En los edificios religiosos son apenas más notables, aunque ni aún en tales casos resulten especialmente elaborados o enfatizados.

Las diferencias continúan, quizás haciéndose más evidentes, al tratarse el tema de las cubiertas. En Cajamarca y en la mayoría de los pueblos de los Andes del norte peruano, sobre las habitaciones del último piso se observa directamente la estructura de madera y caña de los tejados inclinados, sobre la cual una capa de torta de barro sella el conjunto y sirve de apoyo a la cobertura final de tejas cerámicas. En el caso de Huamachuco esto no se da de manera exacta: en todos los niveles, la cubierta se muestra como un techo plano en el que se marcan las vigas y viguetas de la estructura, frecuentemente en rollizo. La torta de barro se encuentra únicamente sobre la estructura inclinada de estos techos planos, siendo inexistente en la sección de la cubierta que se proyecta al exterior como alero. El espacio interno que se configura hasta el techo plano se denomina localmente "terrado" y tradicionalmente se utilizaba como depósito, o incluso como área de secado de productos agrícolas antes de su almacenaje.

Por otra parte, mientras que en general en los Andes los soportes horizontales del extremo del alero - de madera- normalmente continúan hacia el interior de las habitaciones pasando a conformar parte de la estructura de techos planos o inclinados, en Huamachuco los encontramos truncados, visibles apenas como puntos atravesando el ancho del muro perimetral.

Son también de madera todas las estructuras de soporte y circulación en las galerías y escaleras de los patios, así como los balcones: en general esta madera es eucalipto, aunque algunos ejemplos típicamente más trabajados existen en cedro.
Los balcones mencionados se presentan en gran variedad de acabados en Huamachuco, con la inmensa mayoría configurada como de antepecho alineados en el diseño de la fachada con los ejes de los vanos presentes en el primer nivel. Dentro de esta categoría son preponderantes los tipos con una combinación de balaustres "de bulto" y planchas de madera tallada, y en algunos casos notables encontramos ejemplos sin madera pero con fierro torneado, curvándose con un aire casi art- nouveau.

Existen también algunos ejemplares de balcones corridos, aunque en porcentaje significativamente menor $y$ presentando siempre balaustres planos de madera de antepecho y una cubierta plana con apenas molduras.

Los colores exteriores e interiores de las construcciones correspondían tradicionalmente a la materialidad local, puesto que para la coloración dependía de insumos en forma de tierras con pigmento. Así, los muros típicamente eran cubiertos en blanco humo o rosa, mientras que coloraciones marrones oscuras eran preferidas para los zócalos de las fachadas.

\section{ARQUITECTURA DOMÉSTICA EN HUAMACHUCO}

Como es usual en centros urbanos comparables, en Huamachuco la absoluta mayoría de las construcciones históricas son de naturaleza residencial o doméstica, esto es, casas -que podían contener, en origen como hoy, una o más viviendas. ${ }^{18}$

Para estas residencias, se pueden observar un par de configuraciones tipológicas específicas entre el universo revisado, ${ }^{19}$ pero en general podemos hablar siempre de un muro perimetral sin retiro hacia la calle. Atravesado este límite a través de la puerta principal, encontramos

18 Sobre esto, un concepto que ya aparece en la documentación virreinal, han escrito San Cristóbal y Harth-terré, entre otros. La idea es que el edificio físico de la casa contenía las viviendas de una o más familias, cada una ocupando el número de habitaciones necesario para cumplir las funciones domésticas, y en ocasiones compartiendo espacios como los patios o las galerías.

19 Las observaciones aquí presentadas, por supuesto, se refieren a los edificios más o menos preservados que aún pueden observarse en el conjunto, puesto que ha sido imposible hasta la fecha encontrar planos o esquemas gráficos para las casas del siglo XVIII, el de principal interés para Huamachuco. 
en la gran mayoría de los casos un espacio de zaguán, flaqueado por ambientes de tiendas que completan una crujía que ocupa toda la fachada. A esta crujía, típicamente de dos niveles de alto, sigue un patio principal bordeado por una galería techada con columnas de madera escuadrada sobre bases en general rudimentarias de piedra. Esta galería abarca típicamente tres de los lados del patio incluyendo el del ingreso del zaguán. ${ }^{20}$

En el patio, un área rectangular marcada por una fila de gruesas piedras, limita el área cultivable donde crecen rosales, hortensias y flores semejantes. Esta área se encuentra frecuentemente dividida por un camino central que permite acceder directamente a las habitaciones más importantes de la casa, directamente a eje con el zaguán, y bordeada por vegetación. El patio aparece así en Huamachuco como un espacio de recreación pasiva, paseo y refresco para la familia antes que el área de recibimiento y representación que encontramos en otras ciudades de la sierra peruana.

Al otro lado del patio, y directamente centrado en la línea visual del zaguán, se encuentra la puerta principal de una segunda crujía de un solo nivel. Esta segunda crujía contiene un único piso, más alto interiormente que uno de la crujía frontal, lo que hace que en este lado no exista el recorrido de la galería de circulación y la protección esté dada por el alero de la primera habitación.

La "segunda crujía" en realidad son dos, con pavimento entablado: la primera de estas crujías, con vista al primer patio y al zaguán, contiene un gran ambiente de representación central que es fácil inmediatamente relacionar con la tradicional sala. A continuación, otra crujía contiene lo que en la Lima del siglo XVII se llamaría una cuadra, pero que en las casas huamachuquinas estudiadas, más modernas, es el comedor o incluso la cocina. Esta doble crujía tras el patio, conteniente los espacios más amplios e importantes de la residencia, nos habla de un período histórico uniforme para la mayoría de las casas de valor patrimonial remanentes en el conjunto urbano.

Inmediatamente después de estos espacios, aparece típicamente un segundo patio, como el primero rodeado por una galería de columnas. Este patio, como el primero y como el zaguán, está empedrado. Alternativamente, al fondo de la propiedad aparece una huerta, tan amplia como el terreno lo permita.

Una variante de esta tipología preeminente en la ciudad muestra residencias con patio central, pero con crujías de dos niveles a ambos lados del mismo, y galerías a los cuatro lados, para luego continuar a una única crujía y llegar luego a un patio o huerta trasera.

Casas como las descritas muestran la misma invariable sucesión de espacios sin importar la forma específica del lote o la ubicación del mismo en el manzaneo de la ciudad. La situación cambia cuando encontramos una segunda tipología: las casas adosadas, presentes en la plaza principal del asentamiento pero también en otras zonas. Estas podrían interpretarse como un remanente formal de la división de una o más casas tradicionales, aunque no muestran la jerarquía de vanos hacia la calle que se podría esperar si el caso hubiera sido tal realmente, con además otras diferencias importantes.

Estas casas adosadas típicamente muestran dos vanos en el primer piso de fachada, uno que corresponde al sistema de corredor/escalera para acceder al segundo nivel del inmueble, y otro, más grande, para el servicio de un ambiente de la primera crujía que se utiliza como tienda hacia la calle. Inmediatamente después, la casa presenta una segunda crujía y luego un pequeño patio que provee de iluminación y ventilación. Finalmente, un último cuerpo construido cierra el lote. Típicamente, toda la construcción se desarrolla uniformemente en dos niveles. Por este y otros motivos entendemos esta segunda tipología

20 Por lo menos en un caso residencial situado en la plaza principal de Huamachuco, el zaguán ingresa al patio de la casa con un alto arco que esta galería sortea creando una suerte de escalera imperial. Véase calle Balta 450-490. 
como, si no temporalmente posterior, al menos de segunda línea en relación a sus parientes más grandes y desarrolladas.

Finalmente, encontramos una variante de estas casas adosadas, que se configura en lotes irregulares con el vano principal asomado a una esquina ochavada. Estas esquinas son comunes en el centro histórico de la ciudad, y sus vanos típicamente corresponden a una tienda o negocio antes que a la residencia de la casa, con la idea de maximizar el área de su influencia comercial ante los peatones.

\section{DOS EJEMPLOS DE ARQUITECTURA RELIGIOSA: LA CAPILLA DE SAN JOSÉ Y EL CAMPANARIO DE LA IGLESIA MATRIZ}

La influencia cajamarquina se muestra también en un edificio religioso emblemático de Huamachuco: la capilla de San José, colocada sobre una plataforma asociada con el antiguo ushnu incaico y por tanto elevada significativamente por sobre el nivel de la plaza principal del asentamiento moderno.

Esta capilla, de una sola nave, campanarios gemelos y gruesos contrafuertes, muestra un imafronte desnudo de portada donde el vano principal -abierto originalmente con terminación en arco de medio punto pero luego tristemente dividido mediante una puerta de madera rectangular y una ventana vidriada semicircular sobre esta- está enmarcado por la proyección de los muros laterales de la nave, creando un espacio reminiscente de los arcos cobijos de la zona del Colca pero también las llamadas "casas retablo" de la Cajamarca rural. ${ }^{21}$ Alrededor de toda la construcción existe un jardín cercado muy agradable.

La tierra cruda es nuevamente el material principal de la construcción, en la configuración de gruesos muros de tapial enlucidos en yeso, con sobrecimiento de piedra. La cubierta original, probablemente una estructura de par y nudillo, se encuentra hoy oculta tras un falso cielo de conglomerado de madera de pobre calidad. La humedad por lluvia es un problema que se ha manifestado en goteras y manchas de chorreo desde la cubierta exterior hacia las paredes interiores.

El interior del edificio muestra a la única nave flanqueada por mochetas de tapial que marcan los tramos, sin evidenciarse ni ménsulas, ni canes, ni molduras ornamentales. Presenta un coro alto al que se accede por una estrecha escalera de madera y desde el cual a su vez puede accederse a los cuerpos de campanas de los campanarios. Se puede leer aún el arco triunfal hacia el presbiterio, pero su configuración se ha distorsionado con la colocación del falso cielorraso. Las escaleras al presbiterio -nuevas, cinco peldaños de cemento- permiten acercarse al retablo mayor y a la pequeña sacristía tras este. Justo antes del primer peldaño, a ambos lados de la nave aparecen vanos laterales de jambas derramadas, pero hoy los dos se encuentran clausurados y se utilizan como hornacinasde almacenaje.

La capilla es un edificio de capital importancia en la configuración urbana de Huamachuco: no sólo se encuentra elevada respecto a la plaza principal, sino que cierra una calle a eje de ésta y bloquea la paralela con su volumen sobre plataforma. Resulta, por tanto, un hito urbano muy simbólico para la población, que la visita con frecuencia.

Una segunda construcción indiscutiblemente importante para el tejido urbano es la del llamado "campanario". Ubicado en una de las esquinas de la plaza principal, al lado de la iglesia matriz, es visualmente muy importante y frecuentemente se le asocia con la imagen de la ciudad. En términos estrictamente arquitectónicos, no se trata de un campanario si no de una gruesa espadaña sobre un "cubo" rectangular de torre. Este cubo de base es atravesado por un arco que permite la circulación peatonal. Sobre él se observa una logia cerrada nuevamente a los lados por gruesos muros como las "casas retablo" cajamarquinas, sobre la que aparecen primero

${ }_{21}$ Véase Burga Bartra, Manuel. Arquitectura Vernácula Peruana. Lima: Colegio de Arquitectos del Perú, 2010. 
tres vanos para campanas y luego uno sobre estos. Finalmente una cubierta, de madera y tejas cerámicas a dos aguas reproduce la sensación de cobijo con líneas rectas.

Claramente planeado como un anexo de servicio para la iglesia, el campanario ha adquirido relevancia propia y valor histórico e identitario a los ojos de la población, sobre todo al considerar la demolición del resto del conjunto religioso original y su reemplazo por un edificio de fines del siglo XX. Este reemplazo obedeció a las consecuencias primero de un incendio en el presbiterio del edificio original en 1919, y posteriormente al desgaste por lluvias ante la ausencia de cubierta. La portada de piedra que cubría el imafronte desapareció inexplicablemente en este período, mientras además se aprovechó la instancia para famosamente excavar en el pavimento de la iglesia buscando "tapados" o entierros de valor, presumiblemente prehispánicos o del primer virreinato. La nueva iglesia matriz, muy grande y con un lenguaje completamente diferente a la expresión del entorno, se encuentra además orientada de manera ligeramente diferente -según puede apreciarse en fotografías históricas- y ya no contiene los retablos originales, que pasaron -componiendo un nuevo retablo mayor- a la capilla de San José.

\section{REFLEXIONES FINALES}

La evolución histórica del conjunto de Huamachuco nos lo presenta como un asentamiento valorado sobre todo por su posición geográfica y las facilidades que la misma le otorgaba en cuanto punto de conexión y descanso para el acceso los diferentes recursos y ciudades mayores de la región.

Desafortunadamente, existen vacíos importantes en nuestro conocimiento al tratarse también de un asentamiento que permaneció paradójicamente aislado de las transformaciones concentradas en la costa y en la capital del país en los últimos decenios, con consecuencias complejas en aspectos sociales y políticos, y una sensación "fronteriza" caracterizada, por ejemplo, por un período en que se le consideró "zona roja" bajo el ataque del terrorismo interno- de la cual sólo recientemente está empezando a recuperarse.

El momento más rico en cuanto a documentación histórica es sin duda el período virreinal, con las limitaciones propias de tratarse de una ciudad de importancia secundaria para la administración española, pero rico en el enunciado de los recursos explotables, sobre todo mineros y textiles.

Desde la perspectiva arquitectónica, el caso de Huamachuco es interesante particularmente al considerar su relativo aislamiento respecto a los procesos nacionales, y su permanencia como un pueblo/ciudad de escala acotada.

Los materiales preferidos en el conjunto histórico de Huamachuco son, como se ha mencionado, el tapial en los muros y la madera de eucalipto para la carpintería, con piedra únicamente en cimientos y sobrecimientos, y tejas cerámicas en la terminación de la cubierta. Estos materiales determinaron, entre otras cosas, el dimensionamiento de los vanos -en general pequeños, y alejados de aristas en la estructura-, la extensión del alero y en alguna medida las dimensiones internas de los espacios habitables. Esto significa, por supuesto, que las características estéticas, de diseño y de confort finales están fuertemente condicionadas por el aspecto práctico y funcional de la construcción.

Un segundo determinante en el diseño de los edificios tradicionales fue la influencia de la vecina Cajamarca, que puede leerse en una serie de aspectos mencionados líneas arriba. Lo interesante en este punto es que a pesar de la clara relación entre ambos conjuntos, Huamachuco muestra detalles originales que lo individualizan, aunque sean evidentes solo para el especialista. La diferencia más saltante es, por supuesto, la total ausencia de portadas labradas y su remplazo por expresiones más sutiles como proporción de vanos y molduras en la carpintería.

En términos espaciales, las casas tradicionales que persisten en Huamachuco desde sobretodo el siglo XVIII siguen básicamente la línea de las 
casas patio importadas a través de la conquista española, con la particularidad de tener una primera crujía -la que da a la calle- con dos niveles y la crujía principal tras el primer patio y las subsiguientes con únicamente un nivel. Esto se repite en la mayoría de los casos observados, aunque naturalmente el tiempo y los cambios de propietarios han significado modificaciones inevitables y hasta cierto punto corrientes en la arquitectura doméstica. Los zaguanes se han mantenido en la gran mayoría de los casos.

Los edificios de carácter religioso del conjunto indican nuevamente la influencia del área cajamarquina, aunque en una versión que podríamos calificar de "rural", más adaptada al cotidiano y funcional, sin intenciones de impresionar.

En general se trata de una ciudad que conserva suficientes características de su tradición constructiva como para merecer un reconocimiento en cuanto conjunto, con algunas individualidades valiosas dentro del universo de edificios que la representan. La conservación del entorno -el natural y el construido- se presenta como indispensable en estas circunstancias, apuntando a un reconocimiento del valor por parte de la población local, y eventualmente por los posibles visitantes. 


\section{REFERENCIAS}

Alva, L. (2003) Bolívar en La Libertad. Lima: Instituto Víctor Raúl Haya de La Torre. Disponible en Internet http://www4.congreso.gob.pe/congresista/2001/lalva/publicacion/BolivarenLaLibertad1. pdfConsultado el 11 de abril de 2015.

Burga, M. (2010) Arquitectura Vernácula Peruana. Lima: Colegio de Arquitectos del Perú.

Canziani, J. (2009) Ciudad y Territorio en los Andes. Contribuciones a la historia del urbanismo prehispánico. Lima: Fondo Editorial de la Pontificia Universidad Católica del Perú.

Espinoza, W. (1971) Geografía histórica de Huamachuco, creación del corregimiento, su demarcación política, eclesiástica y económica: 1759-1821. Pease G. Y., Franklin (dir.) Historia y cultura. Lima, N. ${ }^{\circ}$ 5, 5-96.

Elías, José F. (2012) La ciudad de Huamachuco eje de desarrollo intermedio en la región La Libertad, en Nos-otros. Lima, N. ${ }^{\circ} 5,17-40$.

Middendorf, Ernst W. (1973) Perú: observaciones y estudios del país y sus habitantes durante una permanencia de 25 años. Tomo III. Lima: UNMSM. Dirección Universitaria de Biblioteca y Publicaciones.

Lumbreras, L. (2013) Los huamachucos: testimonio de una gran cultura. Lima: Asociación Civil Ruta Moche: CEA.

Pease G. Y., Franklin (2007) Los Incas. Lima: Fondo Editorial de la Pontificia Universidad Católica del Perú.

Salcedo, J. (1954) "Síntesis de la Historia de Huamachuco", en Ledesma, LL., Wilfredo (dir.). Impetu: Organo del Centro Cultural Sánchez Carrión. Huamachuco, N. 9, 7-12.

Tauro del Pino, A. (2001) Enciclopedia ilustrada del Perú: síntesis del conocimiento integral del Perú, desde sus orígenes hasta la actualidad. Tomos: VIII y XV. Lima: PEISA.

Wiener, C. (1993) Perú y Bolivia: relato de viaje: seguido de estudios arqueológicos y etnográficos $y$ de notas sobre la escritura y los idiomas de las poblaciones indígenas. Lima: IFEA- UNMSM.

Fecha de recepción: 14 de abril 2015

Fecha de aceptación: 30 de junio 2015 